\title{
Endogenous Plant Hormone Profiles in Growing Campbell Early Grape Berries
}

\author{
Kiyohide Kojima $^{1 *}$, Hiroya Ikarashi ${ }^{2}$, Daigo Andou ${ }^{3}$ and Tatsuya Matsumoto ${ }^{4}$ \\ ${ }^{1}$ Faculty of Agriculture, Niigata University, Niigata 950-2181, Japan \\ ${ }^{2}$ Graduate School of Science and Technology, Niigata University, Niigata 950-2181, Japan \\ ${ }^{3}$ Graduate School of Agriculture, Kyoto University, Kyoto 606-8502, Japan \\ ${ }^{4}$ Niigata Agricultural Research Institute Horticultural Research Center, Niigata 957-0111, Japan
}

To elucidate the profiles of plant hormones involved in growth and ripening of grape fruit at various stages, grape bunches of Campbell Early grape bunches (Vitis labrusca 'Bailey') which were harvested from 14 to 63 days after full bloom (DAFB) were divided into skin, pulp and seeds. Endogenous plant hormones, which included indole-3-acetic acid (IAA), abscisic acid (ABA), trans-zeatin (Z), isopentenyl adenine (iP), jasmonic acid (JA), methyl jasmonate (MeJA), gibberellin ${ }_{1}\left(\mathrm{GA}_{1}\right)$, and gibberellin ${ }_{4}\left(\mathrm{GA}_{4}\right)$, were quantified by liquid chromatography-mass spectrometry (LC-MS). Throughout the sampling period, higher IAA concentrations were maintained in the seeds than those in the skin and pulp. In the seeds, the $\mathrm{Z}$ concentration was highest at 14 DAFB and then decreased rapidly. However, in the skin and pulp, the iP concentration increased over the course of sampling. The ABA concentration in the pulp was high around veraison. The JA concentration in the skin reached $4,100 \mathrm{pmol} \cdot \mathrm{g}^{-1} \mathrm{FW}$ at $27 \mathrm{DAFB}$. The MeJA concentration in the skin also increased rapidly. These results suggest that increases in iP concentration in the skin and pulp are involved in maturation.

Key Words: ABA, cytokinin, GA, IAA, jasmonic acid.

\section{Introduction}

Fruit growth may require interactions among various plant hormones, because the normal fruit growth is induced by the external application of a combination of plant hormones (Vivian-Smith and Koltunow, 1999). Various plant hormones, which are used for uniform ripening and fruit quality improvement, have been studied in non-climacteric fruits such as grapes (Fortes et al., 2015) and strawberries (Symons et al., 2012). In general, abscisic acid (ABA) plays a role in promoting ripening of fruits, whereas auxin, cytokinin (CK), and gibberellin (GA) are considered to play a role in inhibiting ripening (Leopold and Kriedemann, 1964). Grapes show a slight increase in ethylene synthesis and no typical respiration peak (Coombe and Hale, 1973).

Plant hormones synthesized in seeds mainly may promote fruit growth (Varga and Bruinsma, 1976; Naylor, 1984). Especially, the auxin concentration in the seeds of most fruits is higher than that in surround-

Received; March 12, 2020. Accepted; May 4, 2020.

First Published Online in J-STAGE on July 23, 2020.

* Corresponding author (E-mail: kojimaki@agr.niigata-u.ac.jp). ing tissues (Rayle and Cleland, 1992), which is a major factor in cell expansion of fruit tissues. GA triggers the fruit growth and can induce normal fruit growth even without fertilization (Gillaspy et al., 1993).

In grape fruit, there is a period called veraison between the second and third stage of fruit growth, and during veraison chlorophyll degradation, anthocyanin biosynthesis, sugar accumulation, fruit softening and acid reduction all occur (Castellarin et al., 2011).

Bioassays for auxin, GA, CK, and ABA in pulp and seeds of grapes have been reported (Coombe and Hale, 1973; Inaba et al., 1976). However, the reliability of bioassay analyses has been proven to be problematic. Even so, advances in Mass Spectrometry (MS) detectors have led to them being much more reliable than bioassays (Hedden, 1993). Simultaneous analysis of major plant hormones is important, because fruit growth is regulated by various plant hormones (Gillaspy et al., 1993). However, there is no report of simultaneous analysis of major plant hormones of each various tissue of growing grape berries using his this method. Therefore, in this study, we analyzed eight endogenous plant hormones involved in the growing process of grapes using LC-MS: indole-3-acetic acid 
(IAA), trans-zeatin (Z), isopentenyl adenine (iP), gibberellin $_{1}\left(\mathrm{GA}_{1}\right)$, gibberellin ${ }_{4}\left(\mathrm{GA}_{4}\right), \mathrm{ABA}, \mathrm{JA}$, and methyl jasmonate (MeJA). The purpose of this study was to elucidate the phytohormone profiles at various stages of growth and ripening of grape fruit.

\section{Materials and Methods}

\section{Plant materials}

The materials were harvested five times from the 30year-old grapes Campbell Early grapes (Vitis labrusca 'Bailey') in the research orchard of the Niigata Agricultural Research Institute: 14 (July 4), 27 (July 17), 41 (July 31), 50 (August 9), and 63 DAFB (days after full bloom) (August 22) (Fig. 1). Five clusters were collected at each sampling and all the clusters were divided into skin, pulp and seeds with a knife. The skins and seeds of the five clusters were weighed together, and then immersed in $80 \%$ ethanol and stored at $-40^{\circ} \mathrm{C}$ until extraction. The pulps of the five fruit bunches were weighed together and then ground, and the soluble solids were measured with a digital refractometer using about $1 \mathrm{~g}$ of the ground liquid (RP-101, Atago Co., Ltd., Japan). The remaining grinding liquid was immersed in $80 \%$ ethanol and stored at $-40^{\circ} \mathrm{C}$ until extraction.

Extraction, separation and purification of IAA, ABA and JAs

The skin and seeds were homogenized. The three tissues were filtered into a stock solution of about $80 \%$ ethanol. We added 200 pmol of ${ }^{13} \mathrm{C}_{6}$-IAA (Cambridge Isotope Laboratories Inc., USA), $\mathrm{d}_{6}$-ABA (OlChemIm s.r.o., Czech Republic), $\mathrm{d}_{2}$-JA, and $\mathrm{d}_{2}$-MeJA (Tokyo Chemical Industry Co., Ltd., Japan) as internal standards to a stock solution of about $80 \%$ ethanol (equivalent to $1 \mathrm{~g}$ fresh weight). The aqueous sample solution was concentrated using a rotary evaporator. We adjusted the $\mathrm{pH}$ of the concentrated aqueous solution to 2.8 with dilute hydrochloric acid and filtered it through a membrane filter $(0.22 \mu \mathrm{m})$. Partition extraction was

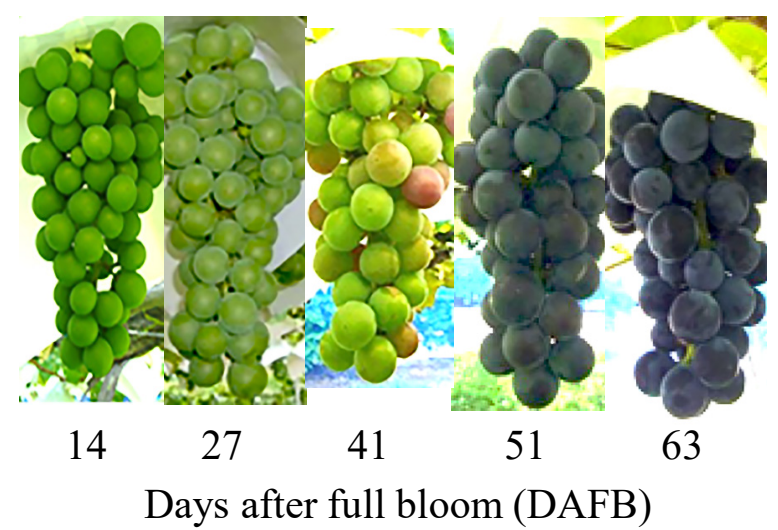

Fig. 1. Photos of typical grape clusters of Campbell Early from 14 to 63 days after full bloom (DAFB). performed with the same amount of diethyl ether, and the diethyl ether layer and aqueous layer were recovered (CKs were present in the diethyl layer and GAs were present in the aqueous layer). The diethyl ether layer was concentrated under reduced pressure to approximately $1 \mathrm{~mL}$ and filtered through a $0.22 \mu \mathrm{m}$ membrane filter.

\section{HPLC for IAA, ABA, and $J A s$}

First HPLC: The extracts were fractionated with a high-performance liquid chromatography (HPLC) system equipped with an ultraviolet detector (Kojima et al., 2002). The HPLC column (Inertsil ODS-3, $3 \mu \mathrm{m}, 10 \times$ $250 \mathrm{~mm}$, GL Sciences Inc., Japan) was isocratically eluted with a solution of $40 \%$ ethanol $+60 \%$ ultrapure water containing $0.1 \%$ acetic acid. Eluates corresponding to the retention times of IAA, ABA, JA, and MeJA were collected separately. IAA and ABA fractions were dried under reduced pressure, and JA and MeJA fractions were concentrated under reduced pressure to approximately $1 \mathrm{~mL}$.

Second HPLC: After fractionation by the "First HPLC", all fractions were further purified with the same HPLC system. The HPLC column (C-30-S-Select, $5 \mu \mathrm{m}, 4.6 \times 250 \mathrm{~mm}$, GL Sciences Inc.) was isocratically eluted with a solution of $40 \%$ ethanol $+60 \%$ ultrapure water containing $0.1 \%$ acetic acid. Fractions of IAA, ABA, JA, and MeJA were injected separately, and eluates corresponding to the retention times of IAA, $\mathrm{ABA}, \mathrm{JA}$, and MeJA were collected. IAA and ABA fractions were dried under reduced pressure, and JA and MeJA fractions were concentrated to approximately $1 \mathrm{~mL}$ under reduced pressure.

Extraction, separation and purification of GAs and CKs Extraction and partition: We added $200 \mathrm{pmol}^{\text {of }} \mathrm{d}_{5^{-}}$ $\mathrm{Z}, \mathrm{d}_{6}-\mathrm{iP}, \mathrm{d}_{2}-\mathrm{GA}_{1}$, and $\mathrm{d}_{2}-\mathrm{GA}_{4}$ (OlChemIm s.r.o., Czech Republic) as internal standards to a stock solution of about $80 \%$ ethanol (equivalent to $9 \mathrm{~g}$ fresh weight). The sample solution was concentrated to approximately $20 \mathrm{~mL}$ under reduced pressure. The $\mathrm{pH}$ of the aqueous layer was adjusted to 3.5 with dilute hydrochloric acid and filtered with a $0.22 \mu \mathrm{m}$ membrane filter. Partition extraction was performed using the same amount of ethyl acetate, and the ethyl acetate and the aqueous layers were recovered (Kojima et al., 2003).

Ethyl acetate layer: Previously reported extraction rates within the ethyl acetate layer for each partition were near $85 \%$ for $\mathrm{GA}_{1}, 98 \%$ for $\mathrm{GA}_{4}$ (Durley and Pharis, 1972), and 60\% for iP (Letham, 1974). Anhydrous sodium sulfate (approximately $1 \mathrm{~g} / 10 \mathrm{~mL}$ ) was added to the ethyl acetate layer $\left(\mathrm{GA}_{1}, \mathrm{GA}_{4}\right.$, and $\left.\mathrm{iP}\right)$ for dehydration and allowed to stand overnight. The ethyl acetate layer was decanted, concentrated under reduced pressure, dissolved in approximately $1 \mathrm{~mL}$ of $50 \%$ ethanol, and filtered through a $0.22 \mu \mathrm{m}$ syringe filter.

The aqueous layer: the $\mathrm{pH}$ of the aqueous layer $(\mathrm{Z}$ 
and $\mathrm{iP}$ ) was adjusted to 7.0 using an $\mathrm{NaOH}$ aqueous solution, partitioned, and extracted with the same amount of butanol. Previously reported extraction rates within the butanol layer for each partition were about $85 \%$ for $\mathrm{Z}$ and $39 \%$ for iP (Letham, 1974). The butanol layer was concentrated under reduced pressure, dissolved in approximately $1 \mathrm{~mL}$ of $50 \%$ ethanol, and filtered through a syringe filter $(0.22 \mu \mathrm{m})$.

\section{HPLC for GAs and CKS}

First HPLC: Extracts from the ethyl acetate and butanol layers were fractionated using the same HPLC system used for the "First HPLC for IAA, ABA, and JAs". Extracts from the ethyl acetate layer were injected into the HPLC system, and eluates corresponding to the retention times of $\mathrm{GA}_{1}, \mathrm{GA}_{4}$, and iP were collected. Extracts from the butanol layer were injected into the HPLC system, and eluates corresponding to the retention times of $\mathrm{Z}$ and iP were collected separately. The iP fractions from the ethyl acetate and butanol layers were mixed. The collected fractions were dried under reduced pressure and the residue was dissolved in $0.3 \mathrm{~mL}$ of $80 \%$ ethanol.

Second HPLC: After fractionation by the "First HPLC" the extracts were further fractionated using the same method for the "Second HPLC for IAA, ABA, and JAs". The fractions of $\mathrm{GA}_{1}, \mathrm{GA}_{4}, \mathrm{Z}$, and iP were injected separately, and eluates corresponding to the retention times of $\mathrm{GA}_{1}, \mathrm{GA}_{4}, \mathrm{Z}$, and iP were collected. The collected fractions were dried under reduced pressure.

\section{Analysis by $L C-M S$}

We used an LC-MS (LCMS 2010EV, Shimadzu Corporation, Japan) to identify the hormones: column, Cadenza CD-C18 $(3 \mu \mathrm{m}, 250 \times 2 \mathrm{~mm}$; Imtakt Corp., Kyoto); flow rate, $0.1 \mathrm{~mL} \cdot \mathrm{min}^{-1}$; and eluent, $70 \%$ ethanol $+30 \%$ ultrapure water $+0.1 \%$ acetic acid. The selected ion monitoring (SIM) method was selected as the analysis mode, and the mode for monitoring ions is shown in Table 1. Plant hormone concentrations were calculated from the ratio of the peak areas of natural and labeled ions as an internal standard (Table 1).

Table 1. Monitored pairs of ions of LC-MS for calculation of endogenous plant hormones.

\begin{tabular}{lllll}
\hline \hline & & & Cold/Label $(\mathrm{m} / \mathrm{z})$ & Mode \\
\hline IAA & \multirow{2}{*}{$130 / 136$} & $176 / 182$ & $\mathrm{IAA} /{ }^{13} \mathrm{C}_{6} \mathrm{IAA}$ & Positive \\
$\mathrm{Z}$ & & $220 / 225$ & $\mathrm{Z} / \mathrm{d}_{5}-\mathrm{Z}$ & Positive \\
$\mathrm{iP}$ & $136 / 137$ & $204 / 210$ & $\mathrm{iP} / \mathrm{d}_{6}-\mathrm{iP}$ & Positive \\
$\mathrm{GA}_{1}$ & & $347 / 349$ & $\mathrm{GA}_{1} / \mathrm{d}_{2}-\mathrm{GA}_{1}$ & Negative \\
$\mathrm{GA}_{4}$ & & $331 / 333$ & $\mathrm{GA}_{4} / \mathrm{d}_{2}-\mathrm{GA}_{4}$ & Negative \\
$\mathrm{ABA}$ & & $263 / 269$ & $\mathrm{ABA} / \mathrm{d}_{6}-\mathrm{ABA}$ & Negative \\
$\mathrm{JA}$ & $209 / 211$ & $\mathrm{JA} / \mathrm{d}_{2}-\mathrm{JA}$ & Positive \\
MeJA & $225 / 227$ & $\mathrm{MeJA} / \mathrm{d}_{2}-$ MeJA & Positive \\
\hline
\end{tabular}

\section{Results}

Changes in skin color, fresh weight and soluble solids

The growth of grape berries was divided into three stages (Fig. 2): Stage I, rapid growth (ca. 0-28 DAFB); Stage II, deceleration of growth (ca. 28-42 DAFB); and Stage III, rapid resumption of growth (ca. 42-71 DAFB) (Inaba et al., 1976). The rapid growth in Stage III was primarily due to cell enlargement of the pulp (Coombe and Hale, 1973). At approximately 42 DAFB, during the veraison period, maturation begins, the skin changes from green to black, sugar accumulates, the fruit softens, and acid decrease begins (Castellarin et al., 2011). In grape berries, cell division in the pulp continues until approximately 10 DAFB, after which the fruit grows with increasing cell volume (Nakagawa and Nanjo, 1965). Cell division in the pericarp continues until about 33 DAFB. The FW of the skin and pulp of grapes of Campbell Early grapes continued to increase during the sampling, but the FW of seeds varied a little (Fig. 2a). The soluble solids of the pulp increased gradually until 27 DAFB, accelerated until 51 DAFB, and increased gradually until 63 DAFB (Fig. 2b). The skin was green at 14 and 27 DAFB, partly red at 41 DAFB around veraison, and black at 50 and 63 DAFB (Fig. 1).

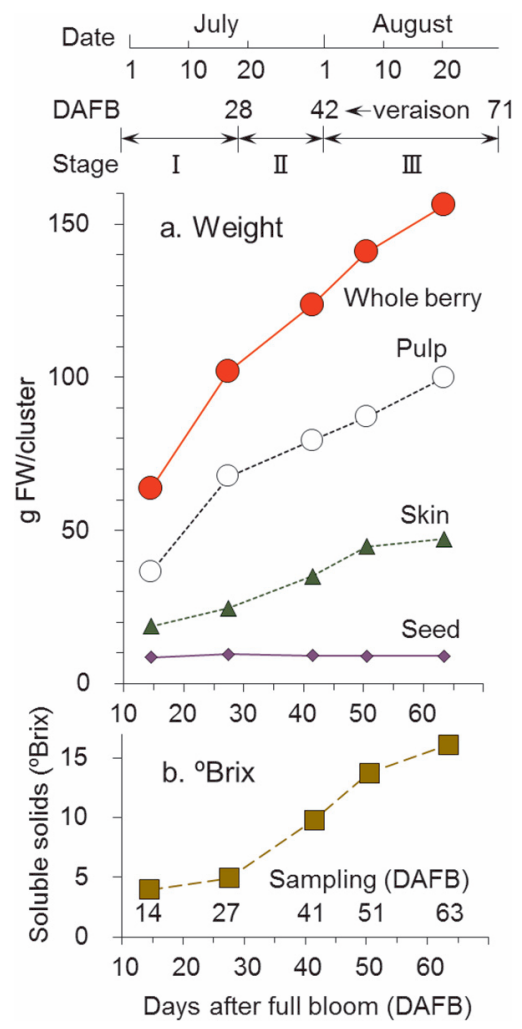

Fig. 2. Changes in weight and soluble solids in the developing Campbell Early grape berries from 14 to 63 DAFB. Five clusters were collected at each sampling, and all the clusters were divided into skin, pulp and seeds with a knife, all tissues were mixed. 


\section{Changes in IAA concentration}

The hormone concentration of whole berries was calculated by summing the amount of seed, pulp, and skin hormones per cluster and dividing this value by the FW per fruit cluster. In the seeds, the concentration of IAA was $158 \mathrm{pmol} \cdot \mathrm{g}^{-1} \mathrm{FW}$ at $14 \mathrm{DAFB}$, but this decreased gradually to $73 \mathrm{pmol} \cdot \mathrm{g}^{-1} \mathrm{FW}$ at $51 \mathrm{DAFB}$ and then increased rapidly to $775 \mathrm{pmol} \cdot \mathrm{g}^{-1} \mathrm{FW}$ (Fig. 3). Throughout the sampling period, the seeds maintained a higher IAA concentration than that in the pulp or skin. At 14 DAFB, the IAA concentration in the skin was $21 \mathrm{pmol} \cdot \mathrm{g}^{-1} \mathrm{FW}$ and that in the pulp was $5 \mathrm{pmol} \cdot \mathrm{g}^{-1} \mathrm{FW}$, however, at 27 DAFB, IAA concentrations in both tissues decreased to $2.4 \mathrm{pmol} \cdot \mathrm{g}^{-1} \mathrm{FW}$ or less (Fig. 3 inset).

\section{Changes in $Z$ and $i P$ concentrations}

The $\mathrm{Z}$ concentration in the seeds was $200 \mathrm{pmol} \cdot \mathrm{g}^{-1} \mathrm{FW}$ at $14 \mathrm{DAFB}$, but decreased to $9.8 \mathrm{pmol} \cdot \mathrm{g}^{-1} \mathrm{FW}$ at 63 DAFB (Fig. 4a). However, throughout the sampling period, the concentration of $\mathrm{Z}$ in the seeds remained higher than that in the pulp and skin. In the pulp, the $Z$ concentration increased from 0.61 to $2.9 \mathrm{pmol} \cdot \mathrm{g}^{-1} \mathrm{FW}$ (14-63 DAFB) (Fig. 4a inset). In the skin, the $\mathrm{Z}$ concentration was as low as $0.25-0.71 \mathrm{pmol} \cdot \mathrm{g}^{-1} \mathrm{FW}$ throughout the sampling period. The iP concentration in the seeds was almost the same level from 14 to 63 DAFB (Fig. 4b). The change in iP concentration was in contrast to that in $\mathrm{Z}$, and the iP concentration in the skin and pulp increased over the course of sampling.

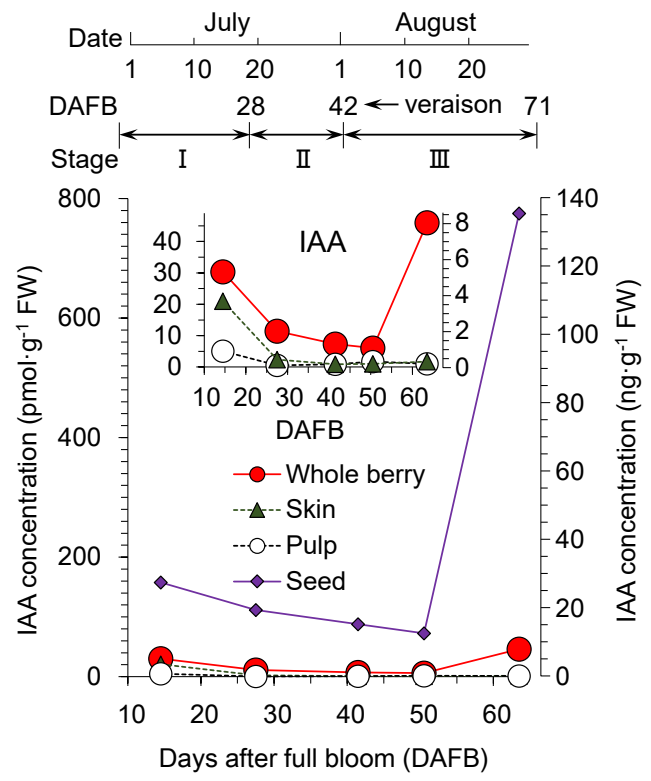

Fig. 3. Changes in endogenous concentration of indole-3-acetic acid (IAA) of whole berries and tissues in developing Campbell Early grape berries from 14 to 63 DAFB. Skin, pulp, and seeds of five clusters at each sampling were mixed. An internal standard was added, then fractionated by extraction with diethyl ether, purified by high performance liquid chromatography (HPLC), and quantified by liquid chromatography-mass spectrometry (LC-MS).

\section{Changes of $G A_{1}$ and $G A_{4}$ concentrations}

The $\mathrm{GA}_{1}$ concentration in the seeds increased slowly from 14 to 42 DAFB, increased rapidly until 51 DAFB, and then decreased rapidly (Fig. 5a). Throughout the sampling period, the GA concentration in the pulp ranged from 0.36 to $0.96 \mathrm{pmol} \cdot \mathrm{g}^{-1} \mathrm{FW}$. In the skin, the $\mathrm{GA}_{1}$ concentration peaked at 27 and 51 DAFB. In the seeds, the highest concentration of $\mathrm{GA}_{4}\left(145 \mathrm{pmol} \cdot \mathrm{g}^{-1} \mathrm{FW}\right)$ was observed at 14 DAFB. This dropped rapidly until 41 DAFB, and then peaked at 51 DAFB (Fig. 5b). In the pulp, the $\mathrm{GA}_{4}$ concentration ranged from 0.55 to $3.0 \mathrm{pmol} \cdot \mathrm{g}^{-1} \mathrm{FW}$ throughout the sampling period and that in the skin peaked at 27 and 51 DAFB (Fig. 5b inset).

\section{Changes in ABA, JA and MeJA concentrations}

The ABA concentration in the seeds was the highest at 14 DAFB, but this decreased until 27 DAFB and then

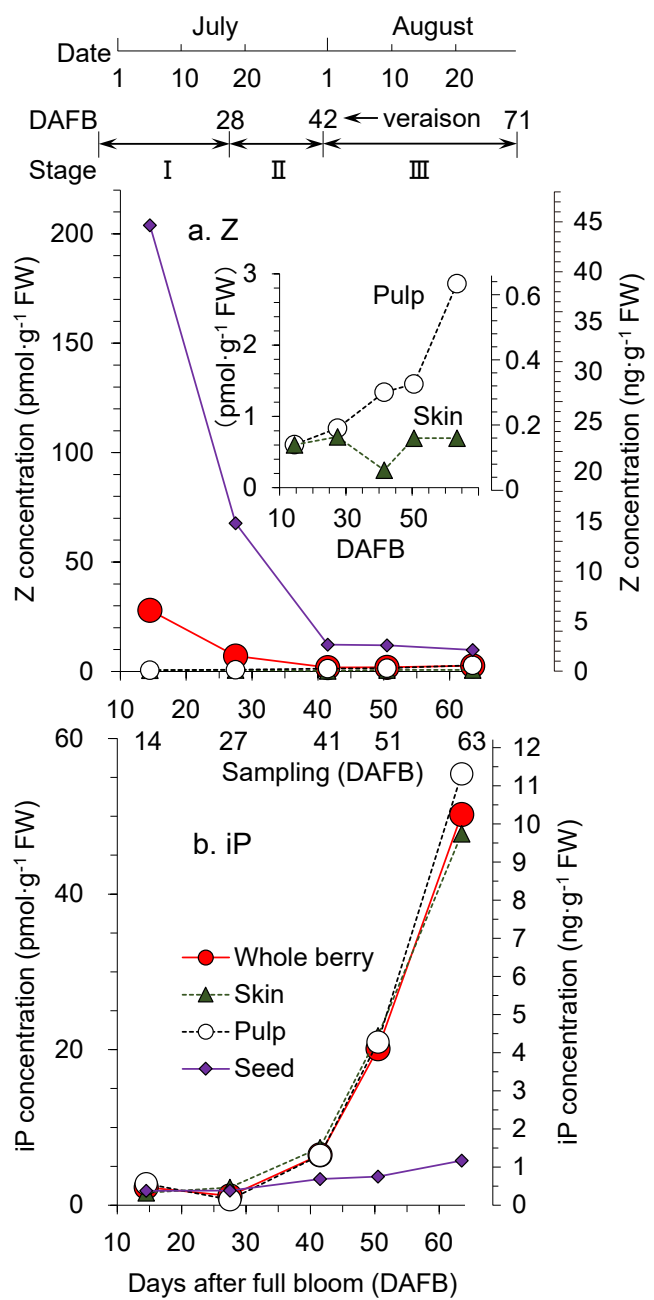

Fig. 4. Changes in endogenous concentration of Trans-zeatin ( $Z$ ) (a) and isopentenyl adenine (iP) (b) of whole berries and tissues in developing Campbell Early grape berries from 14 to 63 DAFB. Skin, pulp and seeds of five clusters at each sampling were mixed. Internal standards were added, then fractionated by extraction with butanol, purified by HPLC, and quantified by LC-MS. 

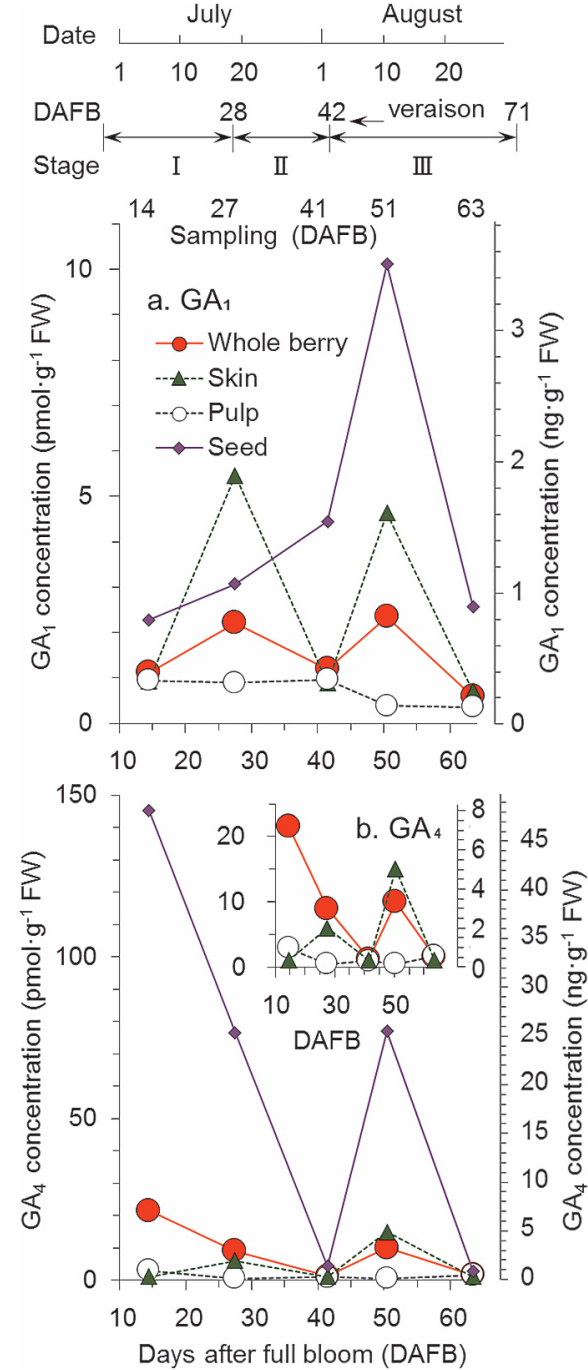

Fig. 5. Changes in endogenous concentration of gibberellins $\left(\mathrm{GA}_{1}\right)(\mathrm{a})$ and gibberellins $4\left(\mathrm{GA}_{4}\right)(\mathrm{b})$ of whole berries and tissues in developing Campbell Early grape berries from 14 to 63 DAFB. Skin, pulp and seeds of five clusters at each sampling were mixed. Internal standards were added, then fractionated by extraction with ethyl acetate, purified by HPLC, and quantified by LC-MS.

remained stable (260-300 $\left.\mathrm{pmol} \cdot \mathrm{g}^{-1} \mathrm{FW}\right)$ (Fig. 6). In the pulp, the ABA concentration rose until 27 DAFB, remained stable at $260-295 \mathrm{pmol} \cdot \mathrm{g}^{-1} \mathrm{FW}$ until $51 \mathrm{DAFB}$, and then decreased. In the skin, the ABA concentration increased from 27 to 63 DAFB.

The JA concentration in the seeds increased until 27 DAFB and continued to decrease thereafter (Fig. 7a inset). In the pulp, the JA concentration ranged from 6 to $96 \mathrm{pmol} \cdot \mathrm{g}^{-1} \mathrm{FW}$ during the sampling period. In the skin, the JA concentration peaked at 27 DAFB $\left(4,100 \mathrm{pmol} \cdot \mathrm{g}^{-1} \mathrm{FW}\right)$ and increased again at $63 \mathrm{DAFB}$ (Fig. 7a). The MeJA concentration in the seeds remained at a low level (Fig. $7 b$ ). In the pulp, the MeJA concentration ranged from 21 to $74 \mathrm{pmol} \cdot \mathrm{g}^{-1} \mathrm{FW}$ during the sampling period, and after 27 DAFB it was lower than that in other tissues. In the skin, the MeJA

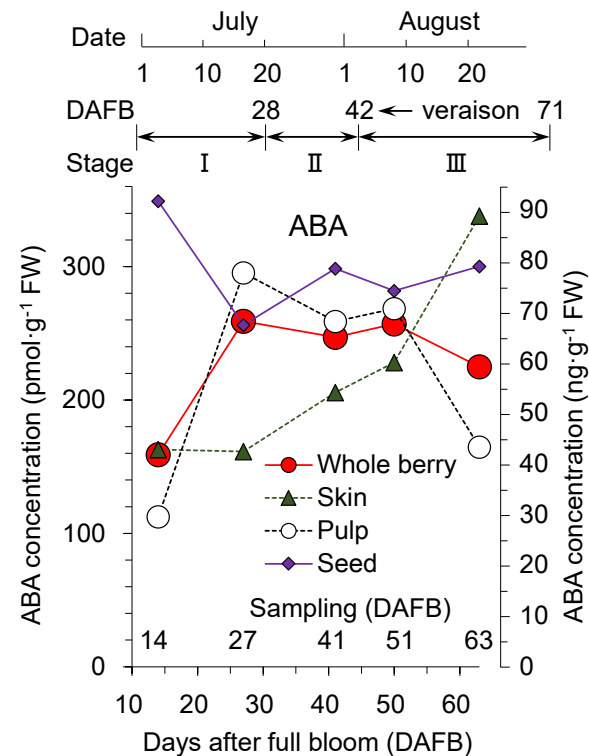

Fig. 6. Changes in endogenous concentration of abscisic acid (ABA) of whole berries and tissues in developing Campbell Early grape berries from 14 to 63 DAFB. Skin, pulp, and seeds of five clusters at each sampling were mixed. An internal standard was added, then fractionated by extraction with diethyl ether, purified by HPLC, and quantified by LC-MS.

concentration rapidly increased until 27 DAFB $\left(3,400 \mathrm{pmol} \cdot \mathrm{g}^{-1} \mathrm{FW}\right)$, decreased until $41 \mathrm{DAFB}$, and stayed at almost the same level thereafter (Fig. 7b).

\section{Discussion}

The roles of plant hormones during berry development

Seeds are a rich source of growth substances that diffuse to surrounding tissues (Mullins et al., 1992). It has been suggested that plant hormones (primarily auxins) synthesized in seeds promote fruit growth (Nitsch, 1971; Varga and Bruinsma, 1976). IAA synthesized in seeds is transported to surrounding tissues to promote cell division and cell expansion, affecting fruit growth (Mullins et al., 1992; Tiwari et al., 2013). In seeds of grapes, the IAA concentration also remained higher than that in the pulp and skin throughout the whole sampling period (Fig. 3). Therefore, it appears that IAA synthesized in grape seeds moves from the pulp to the skin and promotes fruit growth. However, one study has reported that grape seeds do not play a major role in the growth patterns (Peynaud and Ribéreau-Gayon, 1971); the correlation between seed number and berry size was low among seeded varieties. In addition, the seedless variety showed the same double-sigmoid growth pattern as the seeded variety. Further research is expected to elucidate the role of IAA in the seeds.

At 14 DAFB immediately after cessation of cell division, seed $\mathrm{Z}$ had the highest concentration of $200 \mathrm{pmol} \cdot \mathrm{g}^{-1} \mathrm{FW}$ (Fig. 4a). Gillaspy et al. (1993) reported that in tomato CK activity is high in growing seeds and low in surrounding tissues. It has also been reported 


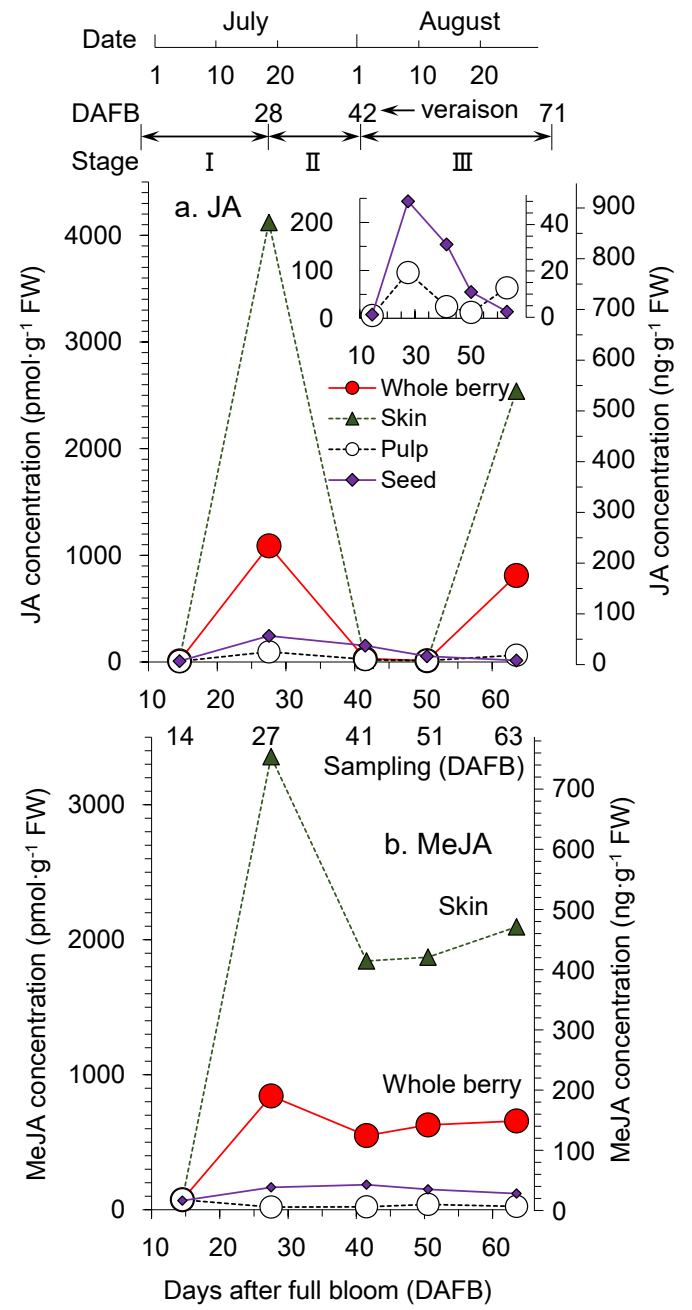

Fig. 7. Changes in the endogenous concentration of Jasmonic acid (JA) (a) and Methyl jasmonate (MeJA) (b) of whole berries and tissues in developing Campbell Early grape berries from 14 to 63 DAFB. Skin, pulp, and seeds of five clusters at each sampling were mixed. Internal standards were added, then fractionated by extraction with diethyl ether, purified by HPLC, and quantified by LC-MS.

that $\mathrm{CK}$ is not synthesized in seeds but may be transported from other tissues (Bohner and Bangerth, 1988). Moreover, Gillaspy et al. (1993) suggested that CK from developing seeds may promote cell division and that in surrounding tissues degrades rapidly. Therefore, the reason for the low $\mathrm{Z}$ concentration of pulp at 14 DAFB is unknown, but high $Z$ in the seeds may contribute to the promotion of cell division of berries after flowering (Fig. 4a).

In grape berries, $\mathrm{GA}_{4}$ was generally at a higher concentration than $\mathrm{GA}_{1}$ (Fig. $5 \mathrm{~b}$ ), suggesting that $\mathrm{GA}_{4}$ is the major GA. In seeds, $\mathrm{GA}_{4}$ at 14 DAFB of Stage I had the highest concentration (Fig. 5b). GA levels in tomato fruits also tended to reach the highest concentration around Stage I (Gillaspy et al., 1993). As a result. the $\mathrm{GA}_{4}$ of the seeds in grape berry seeds in Stage I is suggested to promote rapid berry growth.
The roles of plant hormones during fruit ripening

In the skin and pulp, iP concentrations increased over the course of sampling (Fig. 4b). Böttcher et al. (2015) reported that in grapes, iP levels increased during ripening, suggesting that increased iP is involved in the maturation process. Therefore, the increase in iP concentration in this study also suggests that iP is involved in the maturation process.

Application of GA during fruit growth reportedly delayed ripening in many fruits (Mcdonald et al., 1997; Zilkah et al., 1997). However, in grapes, $\mathrm{GA}_{1}$ and $\mathrm{GA}_{4}$ peaked at 51 DAFB in the Stage III (coloring stage after veraison) (Fig. 5a, b). Further research is needed to resolve the contradiction between the study of external application and GA increase in this study in the coloring phase.

Auxin has been reported to suppress anthocyanin synthesis. External application of auxin slows down the synthesis of anthocyanins, and removing berries (a source of auxin) from strawberry fruits during coloring induces anthocyanins synthesis (Manning, 1993). However, although there were low levels of IAA in all tissues up to 51 DAFB in grapes (Fig. 3), the skin at 51 DAFB was colored (Fig. 1). Therefore no inhibitory effect of IAA on coloring was observed in grapes. The cause and physiological significance of the high concentration of IAA in the seeds at 63 DAFB are unknown (Fig. 3), but there are two possibilities: (1) little transfer of IAA to the pulp due to the enhanced impermeability of substances by the seed coat and (2) rapid metabolism after diffusion to the surrounding pulp.

In grape berries, the ethylene peak occurs before the ABA peak (Sun et al., 2010) and just before veraison in grape berries (Chervin et al., 2004). Sun et al. (2010) suggested that some ABA effects may be mediated by ethylene. Therefore, conducting a study that combines the determination of major endogenous hormones and the measurement of ethylene production will help to elucidate the physiology of grape ripening.

In conclusion, our results revealed an endogenous plant hormone profile in grape fruit growth. The following points were further suggested: 1) The high concentration of $\mathrm{Z}$ in seeds at 14 DAFB immediately after cessation of cell division promotes cell division of berries after flowering. 2) Since $\mathrm{GA}_{4}$ is generally at a higher in concentration than $\mathrm{GA}_{1}, \mathrm{GA}_{4}$ is the main GA. 3) The increase in the iP level of the skin and flesh during the ripening is involved in the maturation process.

\section{Acknowledgements}

The authors would like to thank Mr. Fumitaka Chino for assistance with sampling, Mr. Kiyosi Nezu for the managing of the grape orchard and Mrs. Kyoko Nagahama for creating the graphs and table.

\section{Literature Cited}

Bohner, J. and F. Bangerth. 1988. Effects of fruit set sequence and 
defoliation on cell number, cell size and hormone levels of tomato fruits (Lycopersicon esculentum Mill.) within a truss. Plant Growth Regul. 7: 141-155.

Böttcher, C., C. A. Burbidge, P. K. Boss and C. Davies. 2015. Changes in transcription of cytokinin metabolism and signaling genes in grape (Vitis vinifera L.) berries are associated with the ripening-related increase in isopentenyladenine. BMC Plant Biol. 15: 223. DOI: 10.1186/s12870-015-0611-5.

Castellarin, S. D., G. A. Gambetta, H. Wada, K. A. Shackel and M. A. Matthews. 2011. Fruit ripening in Vitis vinifera: spatiotemporal relationships among turgor, sugar accumulation, and anthocyanin biosynthesis. J. Exp. Bot. 62: 4345-4354.

Chervin, C., A. El-Kereamy, J. P. Roustan, A. Latché, J. Lamon and M. Bouzayen. 2004. Ethylene seems required for the berry development and ripening in grape, a non-climacteric fruit. Plant Sci. 167: 1301-1305.

Coombe, B. G. and C. R. Hale. 1973. The hormone content of ripening grape berries and the effects of growth substance treatments. Plant Physiol. 51: 629-634.

Durley, R. C. and R. P. Pharis. 1972. Partition coefficients of 27 gibberellins. Phytochemistry 11: 317-326.

Fortes, A. M., R. T. Teixeira and P. Agudelo-Romero. 2015. Complex interplay of hormonal signals during grape berry ripening. Molecules 20: 9326-9343.

Gillaspy, G., H. Ben-David and W. Gruissem. 1993. Fruits: a developmental perspective. Plant Cell 5: 1439-1451.

Hedden, P. 1993. Modern methods for the quantitative analysis of plant hormones. Ann. Rev. Plant Physiol. 44: 107-129.

Inaba, A., M. Ishida and Y. Sobajima. 1976. Changes in endogenous hormone concentrations during berry development in relation to the ripening of Delaware grapes. J. Japan. Soc. Hort. Sci. 45: 245-252.

Kojima, K., E. Ohtake and Z. Yu. 2002. Distribution and transport of IAA in tomato plants. Plant Growth Regul. 37: 249-254.

Kojima, K., Y. Tamura, M. Nakano, D. Han and Y. Niimi. 2003. Distribution of indole-acetic acid, gibberellin and cytokinins in apoplast and symplast of parthenocarpic tomato fruits. Plant Growth Regul. 41: 99-104.

Leopold, A. C. and P. E. Kriedemann. 1964. Fruiting. p. 305-336. In: A. C. Leopold and P. E. Kriedemann (eds.). Plant growth and development. McGraw-Hill, New York.

Letham, D. S. 1974. Regulators of cell division in plant tissues XXI. Distribution coefficients for cytokinins. Physiol. Plant. 118: 361-364.

Manning, K. 1993. Soft Fruit. p. 347-377. In: G. B. Seymour,
J. E. Taylor and G. A. Tucker (eds.). Biochemistry of Fruit Ripening. Chapman and Hall, London.

Mcdonald, R. E., P. D. Greany, P. E. Shaw and T. G. Mccollum. 1997. Preharvest applications of gibberellic acid delay senescence of Florida grapefruit. J. Hortic. Sci. 72: 461-468.

Mullins, M. G., A. Bouquet and L. E. Williams. 1992. Developmental physiology: flowering and fruiting. p. 112-146. In: M. G. Mullins, A. Bouquet and L. E. Williams (eds.). Biology of the grapevine. Cambridge University Press, Cambridge.

Nakagawa, S. and Y. Nanjo. 1965. A morphological study of Delaware grape berries. J. Japan. Soc. Hort. Sci. 34: 85-95.

Naylor, A. W. 1984. Functions of hormones at the organ level of organization. p. 172-218. In: T. K. Scott (ed.). Hormonal regulation of development II. Springer, Berlin, Heidelberg.

Nitsch, J. P. 1971. Perennation through seeds and other structures: Fruit development. p. 413-501. In: F. C. Steward (ed.). Plant Physiol. VI, Academic Press, London.

Peynaud, E. and P. Ribéreau-Gayon. 1971. The grape. p. 171205. In: A. C. Hulme (ed.). The biochemistry of fruits and their products. Vol 2. Academic Press, London.

Rayle, D. L. and R. E. Cleland. 1992. The Acid Growth Theory of auxin-induced cell elongation is alive and well. Plant Physiol. 99: 1271-1274.

Sun, L., M. Zhang, J. Ren, J. Qi, G. Zhang and P. Leng. 2010. Reciprocity between abscisic acid and ethylene at the onset of berry ripening and after harvest. BMC Plant Biology 10: 257. DOI: $10.1186 / 1471-2229-10-257$.

Symons, G. M., Y.-J. Chua, J. J. Ross, L. J. Quittenden, N. W. Davies and J. B. Reid. 2012. Hormonal changes during nonclimacteric ripening in strawberry. J. Exp. Bot. 63: 47414750 .

Tiwari, A., A. Vivian-Smith, K. Ljung, R. Offringa and E. Heuvelink. 2013. Physiological and morphological changes during early and later stages of fruit growth in Capsicum annuum. Physiol. Plant. 147: 396-406.

Varga, A. and J. Bruinsma. 1976. Roles of seeds and auxins in tomato fruit growth. Z. Pflanzenphysiol. 80: 95-104.

Vivian-Smith, A. and A. M. Koltunow. 1999. Genetic analysis of growth-regulator-induced parthenocarpy in Arabidopsis. Plant Physiol. 121: 437-451.

Zilkah, S., S. Lurie, Z. Lapsker, Y. Zuthi, I. David, Y. Yesselson, S. Antman and R. Ben Arie. 1997. The ripening and storage quality of nectarine fruits in response to preharvest application of gibberellic acid. J. Hortic. Sci. 72: 355-362. 